Original Research

\title{
Predicting Satellite System Signal Degradation due to Rain in the Frequency Range of 1 to $25 \mathrm{GHz}$
}

\author{
Jacek Wilk-Jakubowski* \\ Kielce University of Technology, Faculty of Electrical Engineering, Automatic Control and Computer Science, \\ Department of Information Systems, Division of Computer Science, \\ 7 Tysiąclecia Państwa Polskiego Ave., 25-314 Kielce, Poland
}

Received: 6 April 2017

Accepted: 20 May 2017

\begin{abstract}
The mechanism of propagation of electromagnetic waves can be approached in different ways. Because all radio waves behave similarly in propagation space, predicting signal degradation due to hydrometeors, abnormal refraction, and the study of selective fading can be done on the basis of measurements from the measuring position. Although some older systems (e.g., microwave beams, propagation by ionospheric reflection) have less importance than new techniques (e.g., fiber-optic links, wireless systems), some systems have been developed to play a meaningful role in communication (e.g., digital television broadcasting via satellites). The part of results connected with noise increase due to precipitation, rain attenuation, and total signal degradation due to rain in the frequency range between 1 and $25 \mathrm{GHz}$, which were collected at the Kielce University of Technology, as a Polish member of COST Action IC0802 - Propagation Tools and Data for Integrated Telecommunication, Navigation, and Earth Observation Systems, is presented in this article.
\end{abstract}

Keywords: increase in noise due to precipitation, atmospheric attenuation, signal attenuation due to precipitation, total signal degradation, radio wave propagation

\section{Introduction}

This article includes studies of the effects of climatic factors with signal degradation. These factors such as: humidity, temperature, fog, and snow cause the urban heat island effect. Research indicate that one of the most important climatic factors is rain [1-5], which can give rise to a lack of communication or interruption of communication due to the signal attenuation and noise

*e-mail: j.wilk@tu.kielce.pl increase. In practice, atmospheric effects are of immense importance for the links operating at frequencies above 10 $\mathrm{GHz}$. At high frequencies of at least $10 \mathrm{GHz}$ or more, the signal degradation due to rainfall increases further.

Measurements in the region of Kielce city seem to be a good indication for system planners doing signal attenuation. Close to this city, at Psary-Katy, there is a large satellite ground station with large parabolic antennae operated by Telekomunikacja Polska. The area of Kielce is a representative region in Poland, especially due to the central location, environment, and morphology of terrain. These factors affect the rain intensity, which exceeds by 0.01 percent the time in an average year $R_{0.01}(\mathrm{~mm} / \mathrm{h})$. 
The environment is particularly important because the severity of rain impairment varies with regional locations. Experience suggests that the $R_{0.01}$ parameter obtained in Kielce is a medium value in Poland. The rain rate $(\mathrm{mm} / \mathrm{h})$ exceeding $0.01 \%$ of the average year in Kielce (one-minute integration time) was estimated to be $34.4 \mathrm{~mm} / \mathrm{h}$. In the article in the $R_{0.01}$ parameter obtained on the basis of the contour map in accordance with the ITU-R recommendation is also presented to show the differences in predicted signal attenuation, noise increase due to precipitation, and total signal degradation between actual data in the long-term perspective in Kielce (40 years in this case) and data from the contour map of the ITU-R, which presents only an approximate $R_{0.01}$ parameter [6-7]. In the recommendation we can find the information about other countries as part of a selected region of the continent [6]. In practice, the $R_{0.01}$ parameter from contour maps of the ITU-R is only approximate to a selected world area. Therefore, we can take into account additionally the valuation of the rain rate $(\mathrm{mm} / \mathrm{h})$, which exceeded by $0.01 \%$ the average year $\left(R_{0.01}\right)$ in Poland (one-minute integration time), meaning 53-minutes per year from the contour map of ITU-R (52.56-minutes accurately, assuming that the year is equal to 365 days) derived from 40 years. It is connected with the availability of a signal equalling $99.99 \%$ (average year) and $99.948 \%$ (worst month), as well as the hours of downtime equalling 0.877 (average year) and 0.379 (worst month). According to ITU-R recommendation No. P.837-6 (ITU-R Rec. P. 837-6), the rain rate $(\mathrm{mm} / \mathrm{h})$ exceeding $0.01 \%$ of the average year $\left(R_{0.01}\right)$ for a location of Poland as a region of Europe equals $R_{0.01}=35 \mathrm{~mm} / \mathrm{h}$, but as we can read from the ITU-R recommendation, this includes data that are not very accurate. We compared this parameter with the result of rain intensity measurements collected by the European Space Agency (ESA, which is the partner of COST ACTION IC 0802) in cooperation with the Institute of Meteorology and Water Management (National Research Institute, IMGW) in Warsaw. Thanks to this approach, we are able to compare these two values and their impact on the attenuation and noise increase due to precipitation and total signal degradation in the frequency range of $1 \mathrm{GHz}$ to $25 \mathrm{GHz}$. Because the long-term 1-min average rainrate characteristics in Kielce as a representative region in Poland is estimated to be $34.4 \mathrm{~mm} / \mathrm{h}\left(R_{0.01}=34.4 \mathrm{~mm} / \mathrm{h}\right)$, the actual rainfall rate statistics in Kielce are smaller than the $R_{0.01}$ parameter obtained on the basis of the contour map of ITU-R Rec. P. 837-6. We should know that the $R_{0.01}$ parameter depends on a location and sometimes could be bigger than it is from ITU-R Rec. P. 837-6, e.g., in: Bielsko-Biała, Bochnia, Bytom, Chełm, Chorzów, Cieszyn, Dębica, Dzierżoniów, Gliwice, Głubczyce, Hrubieszów, Jarosław, Jasło, Katowice, Kraków, Krapkowice, Kraśnik, Krosno, Lębork, Lublin, Miechów, Mielec, Myślenice, Nisko, Nowa Ruda, Nowy Korczyn, Nowy Sącz, Nowy Targ, Nysa, Przemyśl, Przeworsk, Racibórz, Rudnik, Rybnik, Rzeszów, Sandomierz, Sanok, Stalowa Wola, Słupsk, Sosnowiec, Świdnica, Tarnobrzeg, Tarnów,
Tomaszów Lubelski, Ustka, Wałbrzych, Władysławowo, Zabrze, Zakopane, Zamość, and Żywiec.

\section{Results and Discussion}

\section{Experimental Results in Kielce from Laboratory Station}

The Kielce University of Technology was a partner of the research project COST Action IC0802 - Propagation Tools and Data for Integrated Telecommunication, Navigation and Earth Observation Systems [8-10]. We compared the data from the recommendation with the results of rain intensity measurements collected by the ESA in cooperation with the best Polish meteorological and hydrological source of information, which is IMGM. This institute accumulates data introduced into the central

Table 1. $W_{s z}, L_{d}, \quad D N D[\mathrm{~dB}]$ vs. frequency $[\mathrm{GHz}]$ for $R_{0.01}=34.4 \mathrm{~mm} / \mathrm{h}$ (pol. H).

\begin{tabular}{|c|c|c|c|}
\hline$f[\mathrm{GHz}]$ & $L_{d 0.01}[\mathrm{~dB}]$ & $W_{s z}[\mathrm{~dB}]$ & $D N D[\mathrm{~dB}]$ \\
\hline 1 & 0.00 & 0.00 & 0.01 \\
\hline 2 & 0.01 & 0.03 & 0.04 \\
\hline 3 & 0.04 & 0.09 & 0.13 \\
\hline 4 & 0.11 & 0.23 & 0.34 \\
\hline 5 & 0.33 & 0.64 & 0.97 \\
\hline 6 & 0.74 & 1.27 & 2.01 \\
\hline 7 & 1.38 & 2.01 & 3.39 \\
\hline 8 & 2.14 & 2.66 & 4.80 \\
\hline 9 & 2.99 & 3.18 & 6.17 \\
\hline 10 & 3.93 & 3.60 & 7.53 \\
\hline 11 & 4.96 & 3.93 & 8.89 \\
\hline 12 & 6.05 & 4.20 & 10.24 \\
\hline 13 & 7.18 & 4.40 & 11.58 \\
\hline 14 & 8.36 & 4.55 & 12.91 \\
\hline 15 & 9.58 & 4.67 & 14.24 \\
\hline 16 & 10.84 & 4.75 & 15.59 \\
\hline 17 & 12.13 & 4.82 & 16.95 \\
\hline 18 & 13.46 & 4.87 & 18.33 \\
\hline 19 & 14.82 & 4.91 & 19.73 \\
\hline 20 & 16.22 & 4.93 & 21.15 \\
\hline 21 & 17.63 & 4.95 & 22.59 \\
\hline 22 & 19.07 & 4.97 & 24.04 \\
\hline 23 & 20.52 & 4.98 & 25.50 \\
\hline 24 & 21.99 & 4.99 & 26.97 \\
\hline 25 & 23.46 & 4.99 & 28.45 \\
\hline
\end{tabular}


database. Using these data, the actual $R_{0.01}$ parameter derived from 40 years in Kielce was also determined. The discussion includes signal attenuation $L_{d}$, an increase in noise $W_{s z}$, and total signal degradation $D N D$ due to precipitation (which is the sum of these components). The precise tabular data for $R_{0.01}=34.4 \mathrm{~mm} / \mathrm{h}$ are shown in Tables 1 and 2 in the frequency range 1-25 GHz for horizontally and vertically polarized radio waves, respectively.

The results of measurements provided in Tables 1 and 2 we can see in Figs 1 and 2 for horizontally and vertically polarized radio waves, respectively. These indicate that the signal attenuation of horizontally polarized radio waves is greater than the signal attenuation of vertically polarized radio waves above $4 \mathrm{GHz}$. Moreover, an increase in the signal frequency results in the increase in the difference in signal attenuation $L_{d}$ of horizontally and vertically polarized radio waves.

Table 1. $W_{s z}, L_{d}, D N D[\mathrm{~dB}]$ vs. frequency [GHz] for $R_{0.01}=34.4 \mathrm{~mm} / \mathrm{h}$ (pol. H).

\begin{tabular}{|c|c|c|c|}
\hline$f[\mathrm{GHz}]$ & $L_{d 0.01}[\mathrm{~dB}]$ & $W_{s z}[\mathrm{~dB}]$ & $D N D[\mathrm{~dB}]$ \\
\hline 1 & 0.00 & 0.00 & 0.01 \\
\hline 2 & 0.01 & 0.02 & 0.03 \\
\hline 3 & 0.04 & 0.08 & 0.12 \\
\hline 4 & 0.09 & 0.19 & 0.29 \\
\hline 5 & 0.26 & 0.51 & 0.76 \\
\hline 6 & 0.59 & 1.05 & 1.63 \\
\hline 7 & 1.16 & 1.78 & 2.94 \\
\hline 8 & 1.95 & 2.51 & 4.46 \\
\hline 9 & 2.72 & 3.03 & 5.75 \\
\hline 10 & 3.56 & 3.45 & 7.01 \\
\hline 11 & 4.52 & 3.80 & 8.32 \\
\hline 12 & 5.56 & 4.09 & 9.65 \\
\hline 13 & 6.65 & 4.31 & 10.96 \\
\hline 14 & 7.76 & 4.48 & 12.24 \\
\hline 15 & 8.87 & 4.60 & 13.48 \\
\hline 16 & 10.00 & 4.70 & 14.70 \\
\hline 17 & 11.14 & 4.77 & 15.91 \\
\hline 18 & 12.30 & 4.83 & 17.13 \\
\hline 19 & 13.50 & 4.87 & 18.37 \\
\hline 20 & 14.72 & 4.90 & 19.63 \\
\hline 21 & 15.98 & 4.93 & 20.91 \\
\hline 22 & 17.28 & 4.95 & 22.23 \\
\hline 23 & 18.60 & 4.96 & 23.57 \\
\hline 24 & 19.95 & 4.98 & 24.93 \\
\hline 25 & 21.33 & 4.98 & 26.31 \\
\hline
\end{tabular}

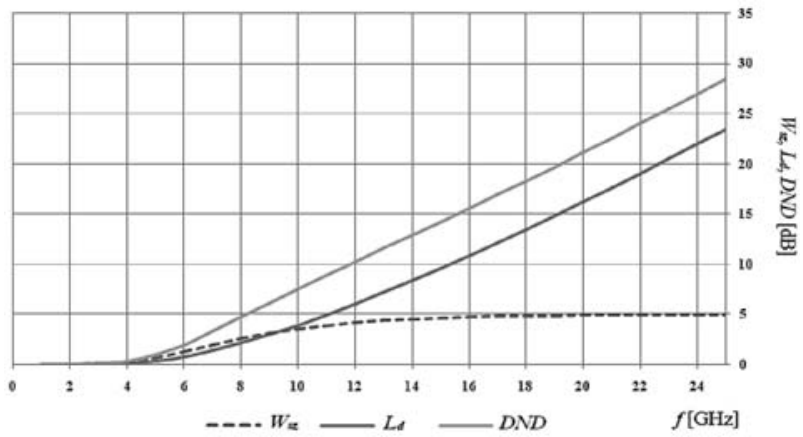

Fig. $1 . W_{s z}, L_{d}, D N D[\mathrm{~dB}]$ vs. frequency $[\mathrm{GHz}]($ pol. $\mathrm{H})$.

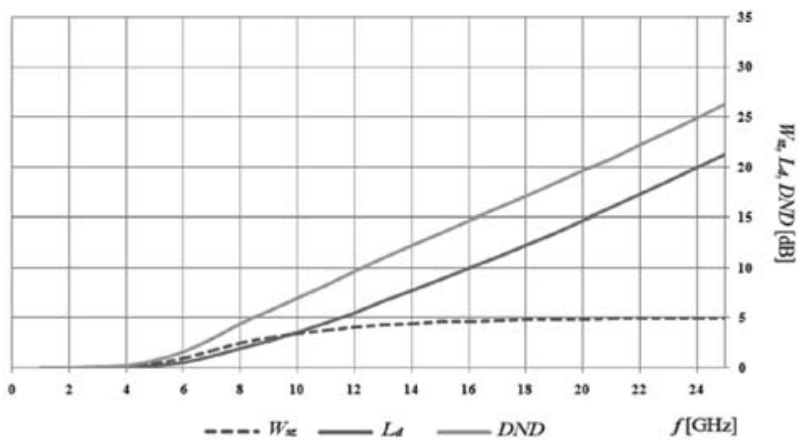

Fig. $2 . W_{s z}, L_{d}, D N D[\mathrm{~dB}]$ vs. frequency $[\mathrm{GHz}]$ (pol. V).

The total signal degradation DND between horizontally and vertically polarized radio waves does not exceed $0.5 \mathrm{~dB}$ in the frequency range $1-9 \mathrm{GHz}, 1 \mathrm{~dB}$ in the frequency range $1-16 \mathrm{GHz}$ and $2 \mathrm{~dB}$ below $23 \mathrm{GHz}$. The maximum difference of total signal degradation DND is equal to $2.14 \mathrm{~dB}$. The difference in noise increase due to precipitation is almost equal to $0 \mathrm{~dB}$ (from $0 \mathrm{~dB}$ to $0.23 \mathrm{~dB}$ ).

For a signal frequency below $17 \mathrm{GHz}$, the difference between horizontally and vertically polarized radio waves does not exceed $1 \mathrm{~dB}$ and below $23 \mathrm{GHz}-2 \mathrm{~dB}$. The maximum difference of signal attenuation $L_{d}$ is approximately equal to $2.13 \mathrm{~dB}$.

Generally, with the increase in frequency we can observe that the difference between signal attenuation $L_{d}$ does not exceed $2.13 \mathrm{~dB}$ (minimum was $0 \mathrm{~dB}$ in the frequency range from $1 \mathrm{GHz}$ to $3 \mathrm{GHz}$ ).

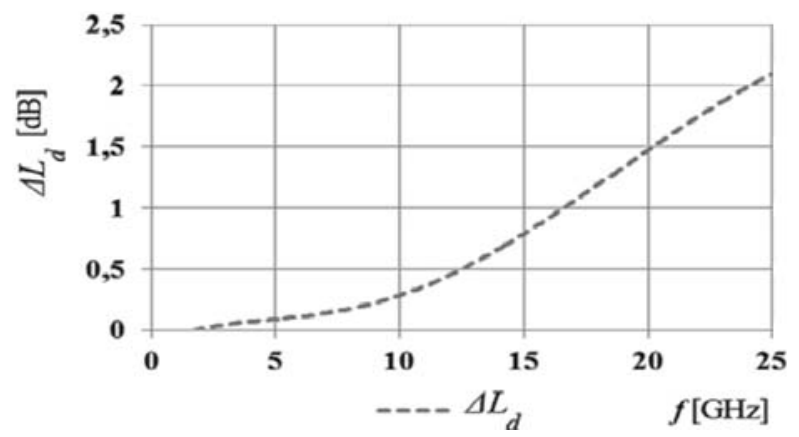

Fig. 3. Increase in $L_{d}[\mathrm{~dB}]$ vs. frequency $[\mathrm{GHz}]$ (pol. H-V). 
Experimental Results in Kielce from the Contour Map of the ITU-R

As we can write from the ITU-R recommendation, the rain rate $(\mathrm{mm} / \mathrm{h})$ exceeding the average year by $0.01 \%\left(R_{0.01}\right)$ on the basis of contour maps is approximate. Therefore, the rain attenuation predicted on the basis of ITU-R Rec. P. 837-6 (also current) is only approximate [6]. ITU-R models were used for the rain attenuation maps.

The results of signal attenuation $L_{d}$, noise increase due to precipitation $W_{s z}$, and total signal degradation $D N D$ (the sum of these components) in the case of rainfall intensity $R_{0.01}=35 \mathrm{~mm} / \mathrm{h}$ for vertically polarized radio waves are shown in Table 4 (pol. V).

We should know that the $R_{001}$ parameter in Kielce derived on the basis of the contour map of the ITU-R is estimated to be $35 \mathrm{~mm} / \mathrm{h}$, so the difference in the $R_{0.01}$ parameter in this location between actual data from the

Table 3. $W_{s z}, L_{d}, D N D[\mathrm{~dB}]$ vs. frequency $[\mathrm{GHz}]$ for $R_{0.01}=35 \mathrm{~mm} / \mathrm{h}$ (pol. H).

\begin{tabular}{|c|c|c|c|}
\hline$f[\mathrm{GHz}]$ & $L_{d 0.01}[\mathrm{~dB}]$ & $W_{s z}[\mathrm{~dB}]$ & $D N D[\mathrm{~dB}]$ \\
\hline 1 & 0.00 & 0.00 & 0.01 \\
\hline 2 & 0.01 & 0.03 & 0.04 \\
\hline 3 & 0.04 & 0.09 & 0.13 \\
\hline 4 & 0.11 & 0.24 & 0.35 \\
\hline 5 & 0.34 & 0.65 & 0.99 \\
\hline 6 & 0.76 & 1.29 & 2.05 \\
\hline 7 & 1.41 & 2.04 & 3.45 \\
\hline 8 & 2.18 & 2.68 & 4.86 \\
\hline 9 & 3.03 & 3.20 & 6.23 \\
\hline 10 & 3.98 & 3.62 & 7.60 \\
\hline 11 & 5.02 & 3.95 & 8.97 \\
\hline 12 & 6.12 & 4.21 & 10.33 \\
\hline 13 & 7.27 & 4.41 & 11.68 \\
\hline 14 & 8.46 & 4.56 & 13.03 \\
\hline 15 & 9.70 & 4.68 & 14.37 \\
\hline 16 & 10.97 & 4.76 & 15.73 \\
\hline 17 & 12.28 & 4.83 & 17.10 \\
\hline 18 & 13.62 & 4.88 & 18.50 \\
\hline 19 & 15.00 & 4.91 & 19.91 \\
\hline 20 & 16.41 & 4.94 & 21.35 \\
\hline 21 & 17.84 & 4.96 & 22.80 \\
\hline 22 & 19.29 & 4.97 & 24.26 \\
\hline 23 & 20.76 & 4.98 & 25.74 \\
\hline 24 & 22.24 & 4.99 & 27.23 \\
\hline 25 & 23.73 & 4.99 & 28.72 \\
\hline
\end{tabular}

laboratory station and contour map of the ITU-R equals $0.6 \mathrm{~mm} / \mathrm{h}$.

In practice, the signal attenuation for horizontally and vertically polarized radio waves for rainfall intensity $R_{0.01}=35 \mathrm{~mm} / \mathrm{h}$ is greater than the signal attenuation for horizontally and vertically polarized radio waves, respectively, for the rainfall intensity obtained on the basis of actual data from the laboratory station $\left(R_{0.01}=34.4 \mathrm{~mm} / \mathrm{h}\right)$. As might be expected, there is still a tendency to observe that the increase in the signal frequency results in an increase in the difference in signal attenuation $L_{d}$ between horizontally and vertically polarized radio waves.

The results for horizontally and vertically polarized radio waves are shown in Figs 4-5 for rainfall intensity $R_{0.01}=35 \mathrm{~mm} / \mathrm{h}$ obtained on the basis of the ITU-R contour map (the detailed data are original and have not been published in articles anywhere else).

Table 4. $W_{s z}, L_{d}, D N D[\mathrm{~dB}]$ vs. frequency $[\mathrm{GHz}]$ for $R_{0.01}=35 \mathrm{~mm} / \mathrm{h}$ (pol. V).

\begin{tabular}{|c|c|c|c|}
\hline$f[\mathrm{GHz}]$ & $L_{d 0.01}[\mathrm{~dB}]$ & $W_{s z}[\mathrm{~dB}]$ & $D N D[\mathrm{~dB}]$ \\
\hline 1 & 0.00 & 0.00 & 0.01 \\
\hline 2 & 0.01 & 0.02 & 0.04 \\
\hline 3 & 0.04 & 0.08 & 0.12 \\
\hline 4 & 0.09 & 0.20 & 0.29 \\
\hline 5 & 0.26 & 0.52 & 0.78 \\
\hline 6 & 0.6 & 1.07 & 1.67 \\
\hline 7 & 1.18 & 1.81 & 2.99 \\
\hline 8 & 1.98 & 2.54 & 4.52 \\
\hline 9 & 2.76 & 3.05 & 5.82 \\
\hline 10 & 3.61 & 3.47 & 7.08 \\
\hline 11 & 4.58 & 3.82 & 8.40 \\
\hline 12 & 5.63 & 4.11 & 9.74 \\
\hline 13 & 6.73 & 4.32 & 11.06 \\
\hline 14 & 7.85 & 4.49 & 12.34 \\
\hline 15 & 8.98 & 4.61 & 13.59 \\
\hline 16 & 10.11 & 4.71 & 14.82 \\
\hline 17 & 11.27 & 4.78 & 16.05 \\
\hline 18 & 12.45 & 4.83 & 17.28 \\
\hline 19 & 13.65 & 4.88 & 18.53 \\
\hline 20 & 14.89 & 4.91 & 19.80 \\
\hline 21 & 16.17 & 4.93 & 21.10 \\
\hline 22 & 17.47 & 4.95 & 22.43 \\
\hline 23 & 18.81 & 4.97 & 23.78 \\
\hline 24 & 20.18 & 4.98 & 25.16 \\
\hline 25 & 21.57 & 4.99 & 26.55 \\
\hline
\end{tabular}




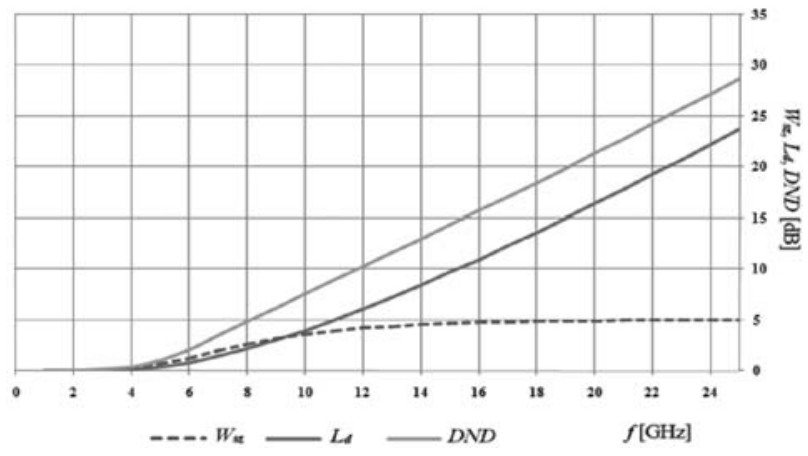

Fig. 4. $W_{s z}, L_{d}, D N D[\mathrm{~dB}]$ vs. frequency $[\mathrm{GHz}]($ pol. $\mathrm{H})$.

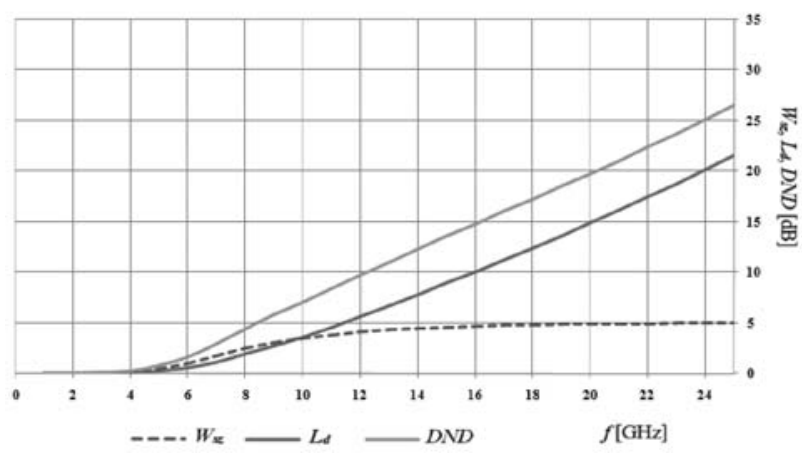

Fig. $5 . W_{s z}, L_{d}, D N D[\mathrm{~dB}]$ vs. frequency $[\mathrm{GHz}]$ (pol. V).

Fig. 5 presents an equivalent diagram but for vertically polarized radio waves.

Unsurprisingly, the results of signal attenuation $L_{d}$ and signal degradation due to rain DND for horizontally and vertically polarized radio waves for the $R_{0.01}=35 \mathrm{~mm} / \mathrm{h}$ parameter (obtained on the basis of the ITU-R contour map) are greater than the results of signal attenuation $L_{d}$ and signal degradation due to rain DND for horizontally and vertically polarized radio waves for the $R_{0.01}=34.4 \mathrm{~mm} / \mathrm{h}$ parameter (obtained on the basis of actual data from the laboratory station), respectively. When we take into account the precise values of rainfall intensity within 40 years in Poland, we could get the most accurate results in signal attenuation $L_{d}$ due to precipitation and, subsequently, total signal degradation DND due to rain in Poland.

\section{Conclusions}

In practice, the climatic factors of rain, humidity, temperature, fog, and snow cause the urban heat island effect. They affect human health as well as signal degradation. Remote sensing is giving the propagation modeling by using a geographic information system. In this particular case, the system could collect aggregated data using multi-scale maps and shall be a local land information system. The maps are useful if we want to define selected regions that meet the requirements in signal quality. Recently, some studies demonstrated that one of the climatic factors is rain [1-5]. The use of climatic data, including rain, helped determine the modeling of suitable areas in cities. Meteorological and remote-sensing data are analyzed and linked to the signal quality information based on the results of radiowave propagation. Due to modeling remote sensing, it is possible to determine rainfall [11-15]. As a consequence, it should be possible to estimate the impact of rain intensity on the quality of a satellite signal. This data can be used in such activities as: emergency management, noise emission maps, monitoring of selected areas, urban space planning, new investment design, and radiowave propagation. Good knowledge about signal attenuation, noise increase, or total signal degradation due to precipitation is fundamental to understanding the propagation mechanism in wireless communication. It is very important to determine the signal degradation findings with satellite systems for planning and management in the city. The sustainable city for planning and management uses to determine the large satellite [11-15].

On the one hand, the use of new techniques is important to satisfy the needs of customers by increased required quality and reducing transmitted power in automatic gain control systems. Because the $R_{0.01}$ parameter obtained in Kielce is a medium value in Poland, it is possible to use of the tabular proceeded data presented in this article. On the other hand, extensive expansion of digital systems leads to frequency spectrum sharing. The effects are undesirable, such as interference between systems or services. One solution to predict attenuation is to use a closely coupled statistical model that performs the lows of physics and the solution of the complex issue by using bilinear interpolation to achieve an improved evaluation from the adjacent grids for a selected region in Poland. The results of measurements can be found in specialized work (series of the ITU-R recommendations and elaborations of COST Action IC0802 - Propagation Tools and Data for Integrated Telecommunication, Navigation and Earth Observation Systems, especially) [16-18]. These data are continuously updated in accordance with the advance of research. Statistical considerations have the benefit of explaining why experimental investigations are necessary (good knowledge about probability calculations is indispensable). Performance of long-term experiments could be put into practice if their results must be sufficiently accurate to justify requiring case-by-case assessment.

The study has an impact on the development of societies, because the data can be used for manufacturers and users of the satellite equipment $[8,10,16,19]$. This is related to the fact that the data transmitted by wireless systems are significantly damping, especially in the troposphere, where weather conditions on the earth are buile. On the basis of the $R_{0.01}$ parameters presented in this article, we can predict rain attenuation and noise increase due to precipitation, and total signal degradation due to rain within all of Poland in the frequency range 1-25 GHz. These data can be useful to satellite engineers for minimizing the risk of lack of communication or interruption of communication due to adverse weather 
conditions, or to determine the link budget analysis of satellite links in a function of many various parameters (including precipitation) to ensure proper reception.

Ongoing research may be used in future work to analyze the propagation of microwave satellite signals above $25 \mathrm{GHz}$ in Poland, or to combine the signal by using a transmultiplexer [20]. Other uses include analyse absorption, determining the link budget, and, among others, to determine the impact of mechanisms affecting the propagation of radio waves to obtain the regression models of signal attenuation or degradation [21-22]

\section{References}

1. CETIN M., ADIGUZEL F., KAYA O., SAHAP A. Mapping of bioclimatic comfort for potential planning using GIS in Aydin. Environment, Development and Sustainability, in press, DOI: 10.1007/s10668-016-9885-5, 1-15, 2016. Available online: http://link.sprin ger.com/article/10.1007/ s10668-016-9885-5 (accessed on 07.02.2017).

2. CETINM. Determining the bioclimatic comfort in Kastamonu City. Environmental Monitoring and Assessment, 187 (10), 640, 2015. Available online: http:// link.springer.com/article 10.1007\%2Fs10661-015-4861-3 (accessed on 07.02.2017).

3. CETIN M. Determination of bioclimatic comfort areas in landscape planning: A case study of Cide Coastline. Turkish Journal of Agriculture-Food Science and Technology, 4 (9), 800, 2016.

4. CETIN M., TOPAY M., KAYA LG., YILMAZ B. Efficiency of bioclimatic comfort in landscape planning process: case of Kutahya. Turkish Journal of Forestry, 1 (1), 83, 2010.

5. CETIN M., SEVIK H. Assessing Potential Areas of Ecotourism through a Case Study in Ilgaz Mountain National Park, 1st ed.; Butowski L., InTech: Rijeka, Croatia, 81, 2016. Available online: http://www.intechopen.com/ books/tourism-from-empirical-research-towards-practicalapplication/assessing-potential-areas-of-ecotourismthrough-a-case-study-in-ilgaz-mountain-national-park (accessed on 07.02.2017).

6. ITU-R. REC. P. 837-6. Characteristics of precipitation for propagation modeling. Available online: http://www.itu.int/ rec/R-REC-P.837-6-201202-I/en (accessed on 27.02.2017).

7. ITU-R. Radio Regulations. Edition of 2016. Available online: http://www.itu.int/en/publications/ITU-R/Pages/ default.aspx (accessed on 02.02.2017).

8. EUROPEAN COOPERATION IN THE FIELD OF SCIENTIFIC AND TECHNICAL RESEARCH - COST. Memorandum of Understanding for the implementation of a European Concerted Research Action designated as COST Action IC0802: Propagation tools and data for integrated Telecommunication, Navigation and Earth Observation systems. Available online: http://w3.cost.eu/fileadmin/ domain_files/ICT/Action_IC0802/mou/IC0802-e.pdf (accessed on 02.02.2017).

9. EUROPEAN COOPERATION IN THE FIELD OF SCIENTIFIC AND TECHNICAL RESEARCH - COST. Final evaluation Report: Propagation Tools and Data for Integrated Telecommunication, Navigation and Earth Observation Systems. Available online: http://w3.cost.eu/ fileadmin/domain files/ICT/Action IC0802/final report/ final report-IC0802.pdf (accessed on 02.02.2017).

10. WILK J. Scientific collaboration in the range of the European Research Project COST IC0802. The East and South in a global dimension. The experiences gained, the prospects for future, 1st ed.; Brzoza R., Miłek M., Wilk-Jakubowski G., Wydawnictwo Stowarzyszenia Współpracy PolskaWschód. Oddział Świętokrzyski: Kielce, Poland, 163, 2012 [In Polish].

11. CETIN M., SEVIK H. Evaluating the recreation potential of Ilgaz Mountain National Park in Turkey. Environmental Monitoring and Assessment, 188 (1), 52, Available online: $\quad \mathrm{http}: / /$ link.springer.com/article/10.1007\%2 Fs10661-015-5064-7 (accessed on 07.02.2017).

12. CETIN M. Using GIS analysis to assess urban green space in terms of accessibility: case study in Kutahya. International Journal of Sustainable Development \& World Ecology, 22 (5), 420, 2015. Available online: http://www.tandfonline. com/doi/full/ 10.1080/13504509.2015.1061066 (accessed on 07.02.2017).

13. CETIN M. Sustainability of urban coastal area management: a case study on Cide. Journal of Sustainable Forestry, 35 (7), 527, 2016. Available online: http://dx.doi.org/10.1080/1054 9811.2016.1228072 (accessed on 07.02.2017).

14. CETIN M. Evaluation of the sustainable tourism potential of a protected area for landscape planning: a case study of the ancient city of Pompeipolis in Kastamonu. International Journal of Sustainable Development \& World Ecology, 22 (6), 490, 2015. Available online: http://www.tandfonline. com/doi/abs/10.1080/13504509.2015. 1081651?src=recsys \&journalCode=tsdw20 (accessed on 07.02.2017).

15. CETIN M. Consideration of permeable pavement in Landscape Architecture. Journal of Environmental Protection and Ecology, 16 (1), 385, 2015. Available online: https://docs.google.com/a/jepe-journal.info/viewer? $\mathrm{a}=\mathrm{v} \& \mathrm{p}$ id=sites\&srcid=amVwZS1qb3 VybmFsLmluZm98amVw ZS1qb3VybmFsfGd4OjNmY2FkYzYzN2Y1MWN1YjM (accessed on 07.02.2017).

16. WILK J. Total signal degradation due to rain precipitation in the troposphere in the area of Kielce city. Scientific Journal. Telecommunications and Electronics, 17 (262), 5, 2013.

17. BOULANGER X., CASTANET L., JEANNIN N., LACOSTE F. Study and modelling of tropospheric attenuation for land mobile satellite system operating at $\mathrm{Ku}$ and $\mathrm{Ka}$ band. COST IC0802 (MCM2). Available online: http://www.tesa.prd.fr/cost/input_documents.pdf (accessed on 02.02.2017).

18. BENARROCH A., GARCÍA-DEL-PINO P., GARCÍARUBIA J. M., RIERA J. M. Derivation of rain attenuation from experimental measurements of drop size and velocity distributions. COST IC0802 (MCM3). Available online: http://www.tesa.prd.fr/cost/ input documents.pdf (accessed on 02.02.2017).

19. WILK-JAKUBOWSKI G. The influence of ICT on the modern societies. The Role of Informatics In Economic and Social Sciences. Innovations and Interdisciplinary Implications, 1, 11, 2011 [In Polish].

20. CIOSMAK J. An algorithm of determining non-separable two-dimensional filer arrays for transmultiplexion systems. Przegląd Elektrotechniczny, 87 (11), 217, 2011 [In Polish].

21. MARCINIAK M., NOSICH A. I., ZINENKO T. L. Accurate Analysis of Light Scattering and Absorption by an Infinite Flat Grating of Thin Silver Nanostrips in Free Space Using the Method of Analytical Regularization, IEEE Journal of Selected Topics in Quantum Electronics, 19 (3), 1, 2013.

22. MAREK M. The use of econometric model of the classical linear regression function for quantitative analysis in economics. The Role of Informatics In Economic and Social Sciences. Innovations and Interdisciplinary Implications, 2, 214-220, 2013 [In Polish]. 